\title{
Effects of sublethal acetamiprid doses on the lifespan and memory-related characteristics of honey bee (Apis mellifera ) workers
}

\author{
Jingliang SHI, Chunhua LiAO, Zilong WANG, Zhijiang Zeng, Xiaobo Wu
}

Honeybee Research Institute, Jiangxi Agricultural University, Nanchang 330045, China

Received 8 November 2018 - Revised 27 May 2019 - Accepted 24 June 2019

\begin{abstract}
Honey bees that leave the hive and collect nectar or pollen from pesticide-treated plants are susceptible to be poisoned. Acetamiprid is a new class of insecticide and a member of the neonicotinoids that has been widely applied in the field for pest control. However, effects of sublethal doses of acetamiprid on worker bees are not yet fully understood. In this study, we examined effects of sublethal doses of acetamiprid on lifespan and memory-related characteristics. Newly emerged worker bees from a single colony were randomly divided into four groups, and this experiment was repeated three times using three different colonies. Three doses $(0.5,1$, and $2 \mu \mathrm{g} / \mathrm{bee})$ of acetamiprid diluted by water were added on the thorax of worker bees while bees were exposed to pure water as a control $(0 \mu \mathrm{g} /$ bee). The lifespan of bees treated with acetamiprid at a concentration over $1 \mu \mathrm{g} / \mathrm{bee}$ was significantly reduced, while there was no significant difference between the $0.5 \mu \mathrm{g} /$ bee group and $0 \mu \mathrm{g} /$ bee group. All three doses of acetamiprid affected the memory-related characteristics of bees, reduced the success of proboscis extension response (PER), affected homing ability, and influenced expression levels of two learning- and memory-related genes compared with the control group. This research confirms that sublethal doses of acetamiprid affect the survival of honey bees.
\end{abstract}

\section{Apis mellifera / Acetamiprid / Sublethal doses / Lifespan / Learning and memory}

\section{INTRODUCTION}

Honey bees play a significant role in agricultural production and in maintaining ecological balance. Apiculture not only provides abundant hive products, such as honey, pollen, royal jolly, wax, and propolis, but also supports the pollination of $73 \%$ of crop species (Klein et al. 2007). In recent years, insecticides have been used widely for pest control, but bees being poisoned have been frequently reported (Greig-Smith et al. 1995; Thompson et al. 2010). Compared with other insect genomes, bee genomes are significantly deficient in coding a number of detoxifying enzymes includ-

Corresponding author: X. Wu, wuxiaobo21@163.com Manuscript editor: James Nieh ing cytochrome P450 monooxygenases (P450s), glutathione-S-transferases (GSTs), and carboxyl/ cholinesterases (CCEs) (Claudianos et al. 2010; Johnson et al. 2010). Pesticides applied to crops mainly include neonicotinoids, pyrethroids, organophosphates, and carbamates, and among them, neonicotinoids are the most widely used around the world (Abrol 2013). Additionally, neonicotinoids have higher selectivity for insects versus mammals than other insecticides (Tomizawa and Casida 2004), which includes acetamiprid, imidacloprid, thiamethoxam, clothianidin, thiacloprid, dinotefuran, nitenpyram, and nithiazine, which are commercially available and sold under a variety of trade names (Fairbrother et al., 2014).

Increasing concerns have been raised about bee declines, and researchers have focused on the new 
insecticide class that includes neonicotinoids (Tan et al. 2014; Abdel-Kader et al. 2017). Researchers have studied the differential toxicity of neonicotinoid insecticides in honey bees through determining the acute LD50 values, and the results showed that the nitro-substituted compounds for imidacloprid, clothianidin, thiamethoxam, dinotefuran, and nitenpyram were the most toxic to honey bees under laboratory conditions, while the cyano-substituted neonicotinoids for acetamiprid and thiacloprid exhibited much lower toxicities (Iwasa et al. 2004). In addition, scholars not only have studied the acute toxicity of insecticides to honey bees but also have paid more attention recently to sublethal effects on honey bees (Thompson 2003; Desneux et al. 2007; Böhme et al. 2016). Sublethal effects have been described as effects on physiology and behavior of an individual that experienced pesticide exposure not immediately resulting in death (Desneux et al. 2007), especially for a bee exposed to fieldrealistic doses of insecticides over the long term. Hillier et al. (2013) found that the mortality of honey bees exposed to fluvalinate rapidly increased as dosages increased, and subsequently negative effects of fluvalinate on learning and memory of honey bees had been assessed using PER conditioning techniques (Frost et al. 2013). Moreover, the seed of crops treated with pesticide also affect honey bees (Cutler and Scott-Dupree 2014; Cutler et al. 2014).

The fact that acetylcholine as an important neurotransmitter in insect brains plays a key role in insect daily behavior is generally acknowledged, while neonicotinoids can selectively bind to insect nicotinic acetylcholine receptors (nAChRs) for efficiently controlling pests (Breer 1987; Bicker 2015). However, neonicotinoids also have commonly potential effects on some non-target insects such as bees (Hassani et al. 2008; Cutler and ScottDupree 2014; Fischer et al. 2014). The neonicotinoid insecticide acetamiprid is a member of a new class of broad spectrum insecticides that is widely applied in agricultural crops, and it is popular due to specific effects on controlling pests that become resistant to other classes of pesticides, such as organophosphates, pyrethroids, and carbamates. Acetamiprid can be widely applied to crops at different times throughout the year, but pollen and nectar from acetamiprid-treated crops can also be contaminated. Therefore, it is inevitable that bees will collect this contaminated food during foraging. When foragers return to their hive after collecting, pesticide-polluted pollen and nectar are transferred to cells in combs. Furthermore, beehives are usually placed near crops for improving the collection efficiency. When crops are being sprayed with pesticides, foraging bees are exposed. Meanwhile, there will be pesticides that diffuse in the air and bees in the beehive will also contact aerosolized pesticides. Then, all individuals in the colony will have been threatened by pesticide residue. Researchers have found that younger bees, especially newly emerged worker bees, are deeply affected by pesticide-polluted bee products (Girolami et al. 2009; Pohorecka et al. 2012). This study examined effects of sublethal acetamiprid doses on honey bee lifespan, learning and memory performance, homing ability, and related gene expression of the glutamate receptor A (GluRA) and the N-methyl-d-as-partic acid receptor (Nmdar) (Kucharski et al. 2007; Zachepilo et al. 2008). The ionic receptor of Nmdar is one of the important excitatory amino acid receptors in the central nervous system, which plays a key role in learning and memory processes. More importantly, the mRNA is expressed in whole brain neurons and glial cells of bees (Zachepilo et al. 2008). GluRA is considered to be the main excitatory neurotransmitter in vertebrate brains in regulating learning and memory, as well as a metabotropic glutamate receptor presenting in invertebrate brains such as honey bees, and it also plays an important role in cell differentiation and synapse formation during the development of the nervous system (Danbolt 2001; Kucharski et al. 2007). The intention is to determine the dose range of acetamiprid that is hazardous to honey bees.

\section{METHODS}

\subsection{Experimental design}

Experimental bee colonies (A. mellifera) were kept in the apiary at the Honeybee Research Institute, Jiangxi Agricultural University, Nanchang, China $\left(28.46^{\circ} \mathrm{N}, 115.49^{\circ} \mathrm{E}\right)$. Three A. mellifera colonies were selected to restrict queens in an 
empty frame to lay eggs for $24 \mathrm{~h}$. Approximately 19 days later, frames with capped brood were removed from each colony and transferred into an incubator $\left(T 35^{\circ} \mathrm{C}\right.$; RH 75\%) for worker bee emergence. Newly emerged worker bees from a single colony were randomly divided into four cages, and each cage had approximately 200 bees. This experiment was repeated three times by using three different colonies.

The acetamiprid (70\% water dispersible granule) used in this experiment was provided by Jiangxi Heyi Chemical Co., Ltd. According to fieldrealistic concentrations of acetamiprid provided by the manufacturer $(50 \sim 500 \mathrm{mg} / \mathrm{L})$, we set three concentrations $(333,667$, and $1333 \mathrm{mg} / \mathrm{L})$ of acetamiprid to apply to bees. Distilled water was used to replace organic solvents to dissolve acetamiprid and obtain desired concentrations. To identify whether sublethal acetamiprid doses affect lifespan and memory-related characteristics of worker bees of $A$. mellifera, bees of each treatment received a drop of $1.5 \mu \mathrm{L}$ acetamiprid solution (containing $0.5,1$, and $2 \mu \mathrm{g}$ /bee acetamiprid) on the thorax respectively while bees received a drop of distilled water as a control $(0 \mu \mathrm{g} / \mathrm{bee})$. After thoracic application of all bees in each treatment, all cages were transferred into an incubator $(T$ $35^{\circ} \mathrm{C}$; $\mathrm{RH} 75 \%$ ) for caged rearing.

\subsection{The survival of worker bees}

After newly emerged worker bees received the topical treatment of acetamiprid, bees of each treatment were kept in a wooden cage and were fed with $50 \%$ sucrose water that did not contain any acetamiprid. Bees were received adequate syrup supply each day and records of mortality were kept in each group until all of the bees died (Liao et al., 2017, 2018).

\subsection{The proboscis extension response (PER) experiments of worker bees}

Newly emerged worker bees were prepared and then received a drop of different acetamiprid doses $(0,0.5,1$, and $2 \mu \mathrm{g} /$ bee $)$ as described above. When bees were kept in an incubator $\left(T 35^{\circ} \mathrm{C}\right.$; $\mathrm{RH} 75 \%$ ) for rearing to the seventh day, PER conditioning experiments were conducted to examine learning and memory performance of worker bees from each treatment group. During PER experiments, approximately 30 bees from each treatment group were captured and immobilized on ice to chill in a short time (3-5 $\mathrm{min}$ ), because researchers have found that ice chilling did not appear to affect the memory of honey bees compared with other cold immobilization methods (Frost et al. 2011). Each bee was bound in a U-shaped metal tube with thin strips of GAFFA tape so that the whole body was fixed, but the head and two prolegs were free. Then, worker bees were fed with two or three drops of $50 \%$ sucrose water and transferred into an incubator $\left(T 35{ }^{\circ} \mathrm{C}\right.$; $\left.\mathrm{RH} 75 \%\right)$ to recover. After more than $2 \mathrm{~h}$ of fasting, bees were taken out of the incubator, and those in a poor state (the head and antennae were inactive when touched) were removed. Finally, the remaining healthy bees were trained and tested for olfactory learning according to the PER method of Letzkus et al. (2006). Two scents, limonene and vanilla, were used as a positive and negative unconditioned stimulus, respectively. The positive stimulus (reward) was using limonene plus $1 \mathrm{M}$ sugar solution while the negative stimulus (punishment) was using vanilla plus saturated salt solution. Bees were trained three times repeatedly to discriminate between these two different scents, and three repeats with an interval of 6 min were given. Then, bees were fed enough sugar and returned to the incubator for overnight storage. Memory tests were performed three times with an interval of $6 \mathrm{~min}$ in each group on the second morning using the above two scents. If a bee's correct responses to the negative and positive stimuli were more than incorrect responses, this bee was considered PER success (Liao et al. 2018).

\subsection{The homing ability experiments}

Approximately 800 fresh individuals from a single colony were unevenly divided into four groups. Bees were treated with different doses of acetamiprid solutions in the same way as described above. Then, bees treated with different doses of acetamiprid were marked with different colors and introduced into a colony (only two or three combs). When marked bees were 20 days 
old, approximately 20 marked bees were caught with tweezers and put into a dark styrofoam containers. A location precisely $1 \mathrm{~km}$ away from the beehive was identified by a global positioning system (GPS). Marked worker bees were released from the location, and all of foragers returned to the hive before dark according to the experimental method adopted by $\mathrm{He}$ et al. (2016). We calculated homing rates in different groups. Each group included three replicates with three different colonies.

\subsection{Relative gene expression related to learning and memory of worker bees}

Freshly worker bees were prepared and treated as above, and then, bees were introduced to the original colonies after being marked with different colors corresponding to four different treatment groups. The experiment colonies received standard breeding by a professional beekeeper. Nine bees were collected from each group at stages of 7 days old and 20 days old, and the heads of three bees from each group in the same day were pooled to form a sample, so that each group included three samples, and each group had three repetitions. Relative expression levels of Nmdar and GluRA were quantified in the heads of 7-day-old and 20-day-old worker bees. RT-qPCR was accomplished by using CFX96 with gene-specific primers listed in Table 1 , and the $\beta$-actin gene was used as an internal control. All samples were measured in triplicate. Relative expression levels of these genes among four groups were calculated with methods adopted by Huang et al. (2012).

\subsection{Statistical analyses}

We analyzed the survival of experimental worker bees according to the Kaplan-Meier method using the SPSS17.0 software. We tested for differences in survival among four groups using log-rank tests in SPSS17.0. The PER, homing rate, and gene expression were further analyzed by using analysis of variance (ANOVA) and multivariate ANOVA; when $P<0.05$, we used the ANOVA test followed with Fisher's LSD test to determine whether there were any differences among different groups.

\section{RESULTS}

\subsection{Effect of acetamiprid on the lifespan of A. mellifera worker bees}

Average lifespans of the $1 \mu \mathrm{g} /$ bee group and $2 \mu \mathrm{g} /$ bee group were significantly lower than those of the $0 \mu \mathrm{g} / \mathrm{bee}$ group and $0.5 \mu \mathrm{g} /$ bee group $\left(\chi^{2}=85.15, \mathrm{df}=3, P<0.001\right.$; Table 2), and the average lifespan of the $2 \mu \mathrm{g} /$ bee group decreased more significantly than that of the $1 \mu \mathrm{g} / \mathrm{bee}$ group $\left(\chi^{2}=7.6\right.$, $\mathrm{df}=1, P=0.007)$. There were no significant differences between the $0 \mu \mathrm{g} / \mathrm{bee}$ group and $0.5 \mu \mathrm{g} /$ bee group $\left(\chi^{2}=2.3, \mathrm{df}=1, P=\right.$ $0.102)$. Over half of the worker bees in the $2 \mu \mathrm{g} /$ bee group died approximately at the age of 15 days, while the highest mortality in bees treated with acetamiprid in the $0 \mu \mathrm{g} / \mathrm{bee}$ group and $0.5 \mu \mathrm{g} /$ bee group was observed at approximately day 20 and later (Fig. 1).

\subsection{Effect of acetamiprid on the PER success rate of $A$. mellifera worker bees}

According to PER conditioning results, the PER success rate of the $0 \mu \mathrm{g}$ /bee group was significantly higher than those of the other acetamiprid-treated groups $\left(F_{3,8}=19.5, \mathrm{df}=\right.$ $3, P<0.001$; Fig. 2). In addition, PER success rates of the $1 \mu \mathrm{g} / \mathrm{bee}$ and $2 \mu \mathrm{g} /$ bee dose groups were both significantly lower than that of the $0.5 \mu \mathrm{g} /$ bee group $\left(F_{2,6}=7.0, \mathrm{df}=2, P=\right.$ $0.027)$, while there was no significant difference between the $1 \mu \mathrm{g} /$ bee group and $2 \mu \mathrm{g} /$ bee group $(P=0.421)$.

\subsection{Effect of acetamiprid on homing ability in A. mellifera worker bees}

Homing rates of worker bees in the $0 \mu \mathrm{g} / \mathrm{bee}$ group was significantly higher than those in the other groups $\left(F_{3,8}=7.2, \mathrm{df}=3, P=0.012\right.$; Fig. 3), while there were no significant differences between the $0.5 \mu \mathrm{g} / \mathrm{bee}, 1 \mu \mathrm{g} / \mathrm{bee}$, and $2 \mu \mathrm{g} /$ bee groups $\left(F_{2,6}=0.1, \mathrm{df}=2, P=0.885\right)$. 
Table 1. Primer sequences of genes for real-time quantitative PCR.

\begin{tabular}{lll}
\hline Gene name & Forward primer $\left(5^{\prime}-3^{\prime}\right)$ & Reverse primer $\left(5^{\prime}-3^{\prime}\right)$ \\
\hline Nmdar & GATCTCAGAGTCGAAGCCCG & ACAGCCTTGGTGTATTCCCG \\
GluRA & TTTCCGCGTCAGTAGCTCTC & CGCATGCTGTATGTTCCACG \\
$\beta$-actin & TCCTGCTATGTATGTCGC & AGTTGCCATTTCCTGTTC \\
\hline
\end{tabular}

\subsection{Effect of acetamiprid on the relative expression of learning- and memory- related genes in $A$. mellifera worker bees}

Relative expression levels of three acetamipridtreated groups of Nmdar and GluRA were both significantly lower than that of the $0 \mu \mathrm{g}$ /bee group (Fig. 4a: $F_{3,32}=23.3$, df $=3, P<0.001$; Fig. 4b: $F_{3,32}=17.5$, df $=3, P=0.001$; Fig. 5b: $F_{3,32}=$ $20.8, \mathrm{df}=3, P<0.001$ ), except the expression of Nmdar in 20-day-old worker bees between the $0.5 \mu \mathrm{g} /$ bee and $0 \mu \mathrm{g} /$ bee groups (Fig. 5a). Nmdar relative expression levels of the $2 \mu \mathrm{g}$ /bee group were significantly lower than those of other groups $\left(F_{3,32}=23.3\right.$, df $\left.=3, P<0.001\right)$, and there were no significant differences between the $0.5 \mu \mathrm{g} /$ bee group and $1 \mu \mathrm{g} /$ bee group $(P=0.623$; Fig. 4a); GluRA relative expression levels of the $1 \mu \mathrm{g} / \mathrm{bee}$ group and $2 \mu \mathrm{g} / \mathrm{bee}$ group were significantly lower than those of the other groups $\left(F_{3}\right.$, $32=17.5, \mathrm{df}=3, P=0.001$ ), while there was no significant difference in the expression level between the $1 \mu \mathrm{g} / \mathrm{bee}$ and $2 \mu \mathrm{g} /$ bee groups $(P=$ 0.257 ; Fig. 4b). Nmdar expression levels of the $1 \mu \mathrm{g} /$ bee group and $2 \mu \mathrm{g} /$ bee group were both

Table 2. Effects of different acetamiprid doses on the average lifespan of Apis mellifera worker bees

\begin{tabular}{llll}
\hline $\begin{array}{l}\text { Groups } \\
(\mu \mathrm{g} / \mathrm{bee})\end{array}$ & $\begin{array}{l}\text { Average lifespan } \\
(\text { Mean } \pm \mathrm{SE})\end{array}$ & Median & Sample size \\
\hline 0.0 & $17.694 \pm 0.381^{\mathrm{a}}$ & 20 & 599 \\
0.5 & $18.657 \pm 0.426^{\mathrm{a}}$ & 21 & 630 \\
1.0 & $15.751 \pm 0.376^{\mathrm{b}}$ & 18 & 738 \\
2.0 & $13.673 \pm 0.446^{\mathrm{c}}$ & 15 & 636 \\
\hline
\end{tabular}

Values (mean $\pm \mathrm{SE}$ ) in the same column with different letters are significantly different (Log-rank test, $P<0.05$ ). significantly lower than that of the $0 \mu \mathrm{g} /$ bee group $\left(F_{2,24}=11.9\right.$, df $=3, P=0.008$; Fig. 5a), and the expression level in the $2 \mu \mathrm{g} /$ bee group was significantly lower than that of the $0.5 \mu \mathrm{g} /$ bee group $(P=0.016)$, while there were no significant differences between the other groups $\left(P_{(0,0.5)}=\right.$ $\left.0.057 ; P_{(0.5,1)}=0.212 ; P_{(1,2)}=0.127\right)$. The significant difference in expression levels of the GluRA gene among the four groups in Fig. 5b were consistent with results shown in Fig. 4 a.

\section{DISCUSSION}

A previous study showed that honey bees prefer food containing neonicotinoid pesticides (Kessler et al. 2015), which suggests that nectar and pollen collected by honey bees may contain more neonicotinoid pesticide residues. Overall, contaminated nectar and pollen are inevitably being collected and transported into the hive, and all individuals are indirect affected in the hive by contaminated nectar and pollen through the social behavior of trophallaxis or food sharing. Wu et al. (2011) have found that pesticide residues in contaminated brood comb could reduce worker bee longevity and development. Recently, a newer work has also found adverse effects of imidacloprid on queens' fecundity, worker bees foraging and hygienic activities, and colony development (Wu-Smart and Spivak 2016). In this paper, our results showed adverse effects of acetamiprid on lifespan, olfactory memory, homing ability, and two learning- and memory-related genes of $A$. mellifera. Results of the survival ability of newly emerged worker bees showed that average lifespans of the higher doses groups $(2 \mu \mathrm{g} /$ bee and $1 \mu \mathrm{g} / \mathrm{bee})$ were significantly lower than those of the lower dose groups $(0.5 \mu \mathrm{g} /$ bee and $0 \mu \mathrm{g} / \mathrm{bee})$, indicating that acetamiprid at more than $1 \mu \mathrm{g} /$ bee could affect the lifespan of honey bees. However, bees that received a drop with 


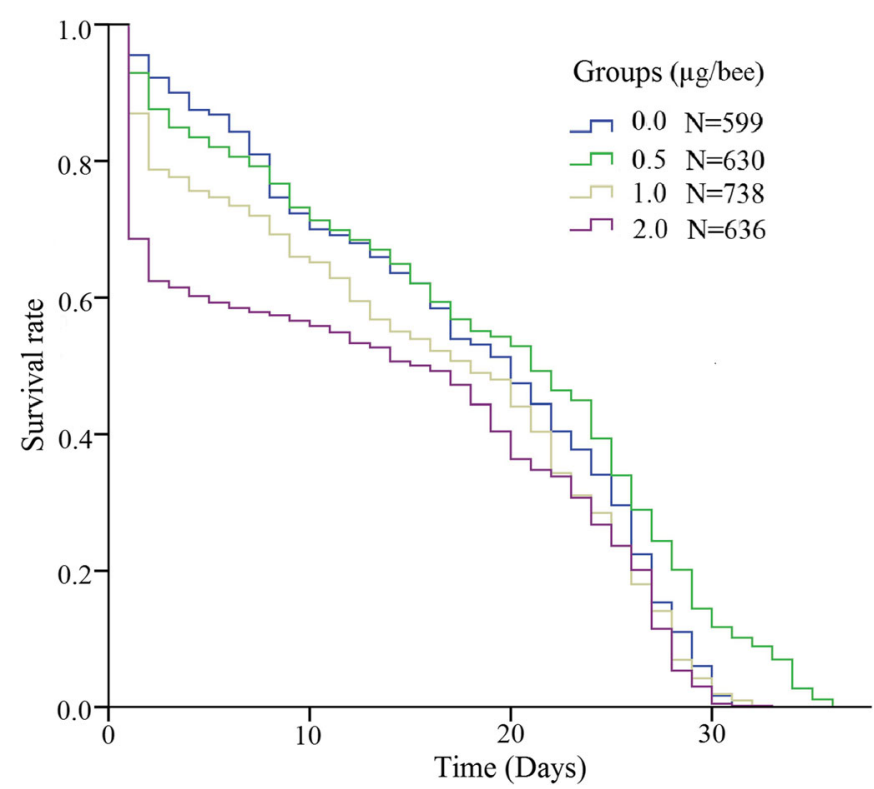

Figure 1. Effects of acetamiprid on the survival of A. mellifera workers, using the Kaplan-estimator of the survival function. $N$ represents the total number of bees in each treatment group

an acetamiprid-treated solution of $0.5 \mu \mathrm{g} / \mathrm{bee}$ showed no significant difference from bees in the $0 \mu \mathrm{g} /$ bee group, and this result was identical to the finding of Hassani et al. (2008).
Social insects, especially for bees, have sophisticated learning and memory abilities, which regulate complex social behaviors (Frost et al. 2012). The olfactory conditioned PER can be used to

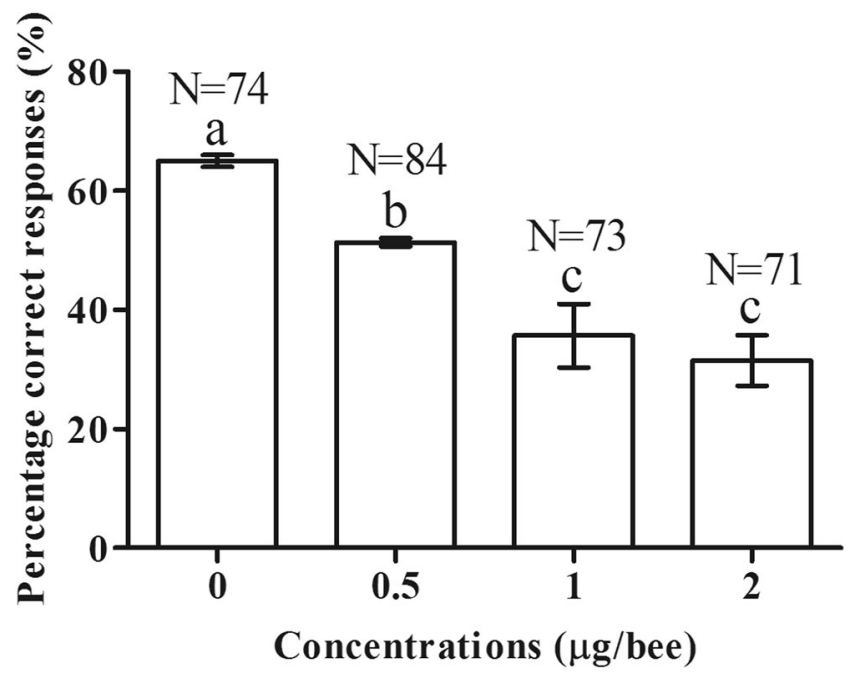

Figure 2. Effects of different doses of acetamiprid on the success rate of PER conditioning. The $X$-axis represents treated concentrations of each group, and the histogram shows the percentage of 7-day-old worker bees that responded correctly in the PER memory test. Each group has a single error bar and shows the mean $\pm \mathrm{SE}$ of three biological replicates. The different letters above the bars indicate significant differences (ANOVA, $P<0.05$ ). $N$ represents the sample size. 


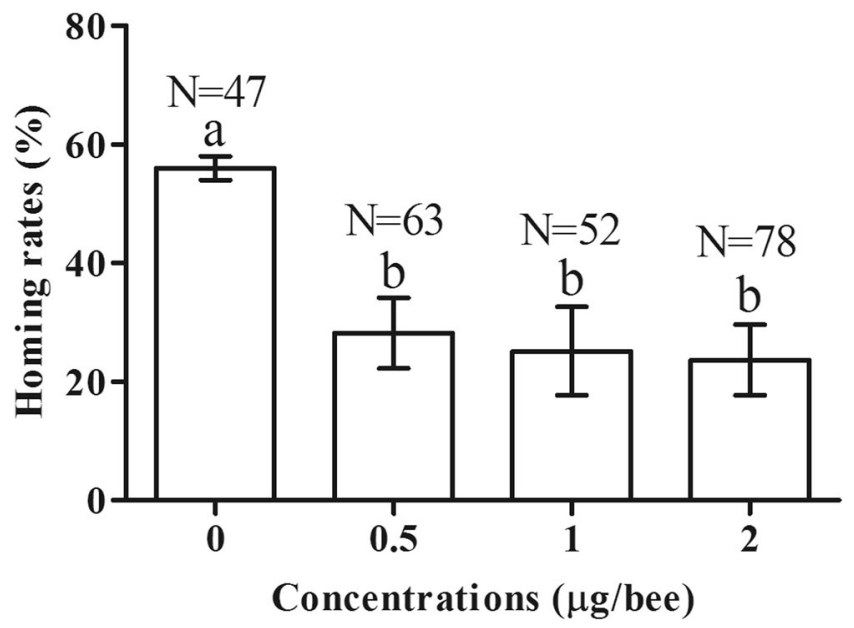

Figure 3. Effects of different concentrations of acetamiprid on homing rates of worker bees released $1 \mathrm{~km}$ away from the hive. The histogram shows the percentage of 20-day-old worker bees that successfully returned to the original hive after being released at $1 \mathrm{~km}$. Each bar shows mean $\pm \mathrm{SE}$ for each treatment group calculated from three values (three biological replicates). The different letters above the bars indicate significant differences $(P<0.05) . N$ represents the total number of released bees.

assess effects of neurotoxic insecticides on learning and memory abilities of A. mellifera worker bees (Lambin et al. 2001; Decourtye et al. 2002, 2004, 2005; Hassani et al. 2005). In this study, our PER results showed that three acetamiprid-treated groups exhibited obviously impaired olfactory memory ability of worker bees. Similar results reported by Thany et al. (2015) showed that lower concentrations (100 ng/bee) of acetamiprid applied on honey bees could impair retention performance. In contrast to results of survival experiments, newly emerged worker bees treated with sublethal doses of acetamiprid of $0.5 \mu \mathrm{g} / \mathrm{bee}$ in
PER were significantly affected. Additionally, homing ability experiments revealed sublethal effects of acetamiprid on cognitive abilities of bees, in which homing rates of three acetamiprid-treated groups $(0.5,1$, and $2 \mu \mathrm{g} / \mathrm{bee})$ were significantly decreased compared with that of the $0 \mu \mathrm{g} / \mathrm{bee}$ group. This is a similar phenomenon to the effects of neonicotinoids on the homing ability of bees (Schneider et al. 2011; Fischer et al. 2014; Stanley et al. 2016). However, there were no significant differences among the three acetamiprid-treated groups. We speculate that the $0.5 \mu \mathrm{g} / \mathrm{bee}$ acetamiprid dose may reach a threshold value on
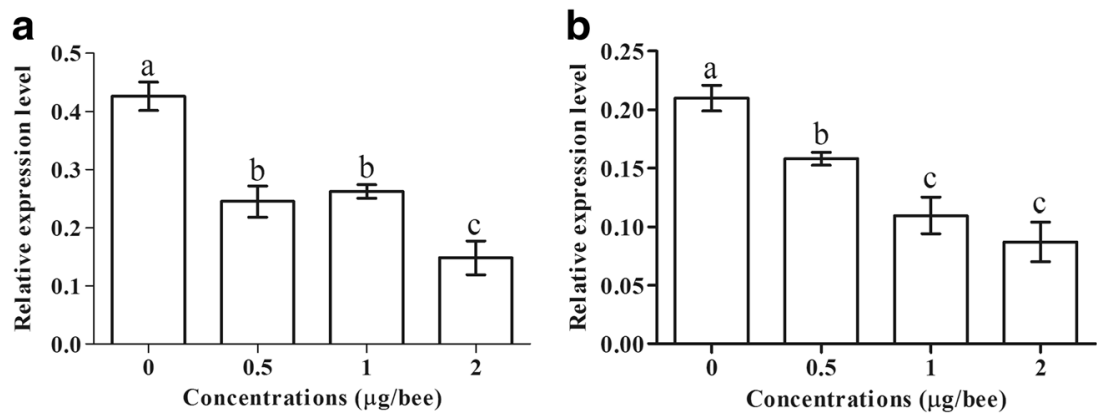

Figure 4. Effects of different concentrations of acetamiprid on relative expression levels of learning- and memoryrelated genes Nmdar (a) and GluRA (b ) of 7-day-old worker bees. 

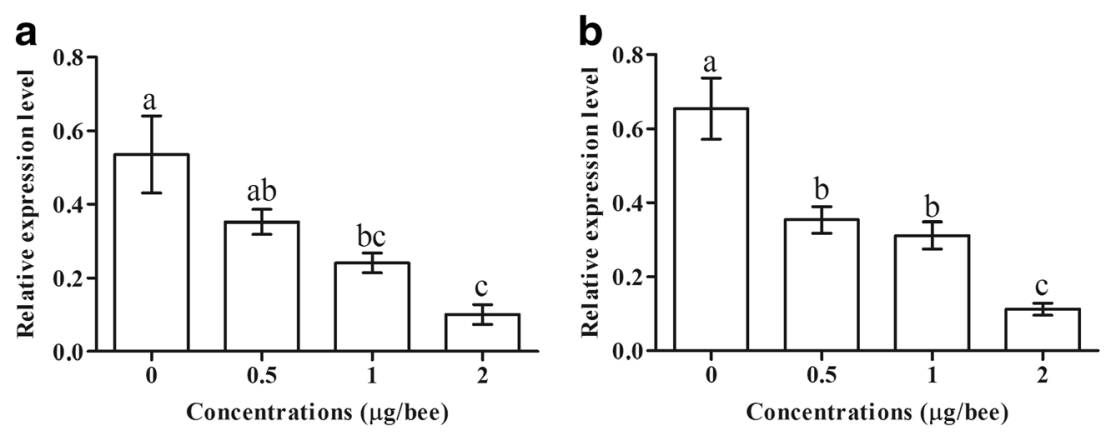

Figure 5. Effects of different concentrations of acetamiprid on relative expression levels of learning- and memoryrelated genes Nmdar (a) and GluRA (b ) of 20-day-old worker bees.

affecting the navigational behavior of bees and that increasing the doses of acetamiprid (such as $1 \mu \mathrm{g} / \mathrm{bee}$ and $2 \mu \mathrm{g} / \mathrm{bee}$ ) will increase risks of bee death. Our research results also indicated that acetamiprid as a new insecticide class had a negative effect on the cognitive ability of bees.

Genes involved in learning and memory of honey bee have been frequently reported (Fiala et al. 1999; Dacher and Gauthier 2008). Wang et al. (2013) obtained hundreds of genes related to learning and memory in the A. mellifera using a tagbased digital gene expression (DGE) method. In this study, two learning- and memory-related genes, N-methyl-d-aspartic acid receptor gene (Nmdar) and glutamate receptor A gene (GluRA), were selected for analysis. Results of the RT-qPCR analysis showed that relative expression levels of Nmdar and GluRA of 7-day-old worker bees in the $0 \mu \mathrm{g}$ /bee groups were significantly higher than those in the other dose groups (Fig. 4a, b), which was consistent with results of the PER experiment (Fig. 2). Nmdar is an important excitatory amino acid receptor in the central nervous system and GluRA is a metabotropic glutamate receptor gene distributed in the central nervous system, the two genes involve in processes of learning and memory (Morris et al. 1990; Danbolt 2001; Kucharski et al. 2007; Zachepilo et al. 2008). These results also indicated that the nervous system of bees can be damaged by doses higher than $0.5 \mu \mathrm{g} / \mathrm{bee}$ of acetamiprid, thereby reducing learning and memory abilities and homing ability. There were no significant differences in relative expression levels of the GluRA gene of 7-day-old worker bees between the $1 \mu \mathrm{g} /$ bee and $2 \mu \mathrm{g} /$ bee groups, while both were significantly lower than that of the $0.5 \mu \mathrm{g} /$ bee group, which indicated that the $1 \mu \mathrm{g} /$ bee dose of acetamiprid more seriously affected expression levels of GluRA. However, relative expression levels of the Nmdar gene in 7-day-old worker bees in the $2 \mu \mathrm{g}$ /bee group were significantly lower than that in the $1 \mu \mathrm{g}$ /bee group while there was no significant differences between the $1 \mu \mathrm{g} / \mathrm{bee}$ group and $0.5 \mu \mathrm{g} /$ bee group, which suggested that there are different regulatory mechanisms for the Nmdar gene and GluRA gene in brains of honey bees. This difference may be related to different responses of excitatory neurons in the bee brain to external factors. Results in Fig. 5a and $b$ show that relative expression levels of Nmdar and GluRA genes of 20-day-old worker bees in the $0 \mu \mathrm{g} / \mathrm{bee}$ group were also significantly higher than those in the $1 \mu \mathrm{g} /$ bee group and $2 \mu \mathrm{g} /$ bee group, while there was no significant difference between the $0.5 \mu \mathrm{g} / \mathrm{bee}$ group and $1 \mu \mathrm{g} / \mathrm{bee}$ group. Relative expression levels of Nmdar of 20-day-old worker bees show no significant difference between the $0 \mu \mathrm{g} /$ bee group and $0.5 \mu \mathrm{g} /$ bee group while the expression of GluRA of 20-day-old worker bees in the $0 \mu \mathrm{g} /$ bee group was higher than that of the $0.5 \mu \mathrm{g} / \mathrm{bee}$ group. The reason may be that genes of GluRA and Nmdar have different regulatory mechanisms which need to be further studied.

\section{CONCLUSIONS}

Our results indicated that the exposure to acetamiprid at a dose greater than $0.5 \mu \mathrm{g} /$ bee to newly worker bees negatively affect survival and memory-related characteristics of worker bees. It 
is worth mentioning that the field dosage of acetamiprid directed by the manufacturer is the range of $50 \sim 500 \mathrm{mg} / \mathrm{L}$ and bees in the beehive around crops are easily poisoned when crops are being sprayed with acetamiprid. We recommend that bees should be moved away when crops are sprayed with acetamiprid.

\section{AUTHOR CONTRIBUTIONS}

$\mathrm{XB} \mathrm{Wu}$ and $\mathrm{ZJ}$ Zeng conceived this research and designed experiments; ZL Wang and $\mathrm{CH}$ Liao participated in the design and interpretation of the data; XB Wu and JL Shi performed experiments and analysis; XB Wu and JL Shi wrote the paper and participated in the revisions of it. All authors read and approved the final manuscript.

\section{FUNDING INFORMATION}

This work was financially supported by the National Natural Science Foundation of China (No. 31760714), the Outstanding Young Talent Program of Jiangxi Province (No. 20162BCB23029), and the Natural Science Foundation of Jiangxi Province (20171BAB204012).

Effets des doses sublétales d'acétamipride sur la durée de vie et les caractéristiques liées à la mémoire des abeilles ouvrières (Apis mellifera)

Apis mellifera / acétamipride / doses sublétales / durée de vie / apprentissage et mémoire

Effekte von subletalen Acetamiprid-Dosen auf die Lebensdauer und auf erinnerungsabhängige Eigenschaften von Arbeitsbienen (Apis mellifera)

Apis mellifera / Acetamiprid / sublethale Dosen / Lebensdauer / Lernen

\section{REFERENCES}

Abdel-Kader, SAS, Abdel-Lateef, M.F., Abdelmonem, A.E. et al. (2017) Effect of sub-lethal concentrations of the insecticides imidacloprid, acetamiprid, thiametoxam and deltamethrin on the foraging behavior of honeybee (Apis mellifera L.). Middle East J. Agric. Res. 6 (2),323-329.

Abrol, D.P. (2013) Safety of Bees in Relation to Pest Management. Asiatic Honeybee Apis cerana . Springer, Dordrecht.

Bicker, G. (2015) Histochemistry of classical neurotransmitters in antennal lobes and mushroom bodies of the honeybee. Microsc. Res. Tech. 45 (3), 174-183.

Böhme, F., Bischoff, G., Zebitz, C.P. et al . (2016) Chronic exposure of honeybees, Apis mellifera (hymenoptera: apidae), to a pesticide mixture in realistic field exposure rates. Apidologie, 48(3), 1-11.

Breer, H. (1987) Neurochemical aspects of cholinergic synapses in insect brain. J. Biomech. 39 (06): S647.

Claudianos, C., Ranson, H., Johnson, R.M. et al. (2010) A deficit of detoxification enzymes: pesticide sensitivity and environmental response in the honeybee. Insect Mol. Biol. 15(5), 615-636.

Cutler, G.C., Scott-Dupree, C.D. (2014) A field study examining the effects of exposure to neonicotinoid seedtreated corn on commercial bumble bee colonies. Ecotoxicology, 23 (9), 1755-1763.

Cutler, G.C., Scott-Dupree, C.D., Sultan, M. et al . (2014) A large-scale field study examining effects of exposure to clothianidin seed-treated canola on honey bee colony health, development, and overwintering success. PeerJ, 2, e652.

Dacher, M., \& Gauthier, M. (2008) Involvement of nosynthase and nicotinic receptors in learning in the honey bee. Physiol. Behav. 95(1), 200-207.

Danbolt, N.C. (2001) Glutamate Uptake. Prog. Neurobiol. 65, 1-105.

Desneux, N., Decourtye, A., Delpuech, J.M. (2007) The sublethal effects of pesticides on beneficial arthropods. Annu. Rev. Entomol. 52 (1),81-106.

Decourtye, A., Devillers, J., Cluzeau, S. et al. (2004) Effects of imidacloprid and deltamethrin on associative learning in honeybees under semi-field and laboratory conditions. Ecotoxicol. Environ. Saf. 57 (3): 410-419.

Decourtye, A., Devillers, J., Genecque, E. et al. (2005) Comparative sublethal toxicity of nine pesticides on olfactory learning performances of the honeybee Apis mellifera. Arch. Environ. Contam. Toxicol. 48 (2): 242-250.

Decourtye, A., Pham-Delègue, M.H., Devillers, J. et al. (2002) The proboscis extension response: assessing the sub-lethal effects of pesticides on the honey bee. Ecotoxicol. Environ. Saf. 57 (3): 410-419.

Fairbrother, A., Purdy, J., Anderson, T. et al. (2014) Risks of neonicotinoid insecticides to honeybees.[J]. Environ. Toxicol. Chem. 33 (4),719-731.

Fiala, A., Müller, U., \& Menzel, R. (1999) Reversible downregulation of protein kinase a during olfactory learning using antisense technique impairs long-term memory formation in the honeybee, Apis mellifera. J. Neurosci. 19 (22), 10125-10134. 
Fischer, J., Müller, T., Spatz, A.K. et al. (2014) Neonicotinoids interfere with specific components of navigation in honeybees. PLoS ONE, 9(3): e91364.

Frost, E.H., Shutler, D., \& Hillier, N.K. (2011) Effects of cold immobilization and recovery period on honeybee learning, memory, and responsiveness to sucrose. J. Insect Physiol., 57 (10), 1385-1390.

Frost, E.H., Shutler, D., \& Hillier, N.K. (2012) The proboscis extension reflex to evaluate learning and memory in honeybees (Apis mellifera): some caveats. Naturwissenschaften, 99 (9), 677-686.

Frost, E.H., Shutler, D., \& Hillier, N.K. (2013) Effects of fluvalinate on honey bee learning, memory, responsiveness to sucrose, and survival. J. Exp. Biol. 216 (15), 2931-2938.

Girolami, V., Mazzon, L., Squartini, A. et al. (2009) Translocation of neonicotinoid insecticides from coated seeds to seedling guttation drops: a novel way of intoxication for bees. J. Econ. Entomol. 102 (5),1808-1815.

Greig-Smith, P.W., Thompson, H.M., Hardy, A.R. et al. (1995) Incidents of poisoning of honeybees (Apis mellifera ) by agricultural pesticides in Great Britain 1981-1991. Crop Prot. 13 (8), 567-581.

Hassani, A.K.E., Dacher, M., Gary, V. et al. (2008) Effects of sublethal doses of acetamiprid and thiamethoxam on the behavior of the honeybee (Apis mellifera). Arch. Environ. Contam. Toxicol. 54 (4): 653-661.

Hassani A.K.E., Dacher, M., Gauthier, M. et al. (2005) Effects of sublethal doses of fipronil on the behavior of the honeybee (Apis mellifera). Pharmacol. Biochem. Behav. 82 (1): 30-39.

He, X.J., Tian, L.Q., Wu, X.B., et al. (2016) RFID monitoring indicates honeybees work harder before a rainy day. Insect. Sci. 3 (1),157-159

Hillier, N. K., Frost, E. H., \& Shutler, D. (2013) Fate of dermally applied miticides fluvalinate and amitraz within honey bee (hymenoptera: apidae) bodies. J. Econ. Entomol. $106(2), 558-565$.

Huang, Q., Kryger, P., Conte, Y.L. et al. (2012) Survival and immune response of drones of a Nosemosis tolerant honey bee strain towards $N$. ceranae infections. J. Invertebr. Pathol. 109 (3),297-302.

Iwasa, T., Motoyama, N., Ambrose, J.T. et al. (2004) Mechanism for the differential toxicity of neonicotinoid insecticides in the honey bee, Apis mellifera. Crop Prot. 23 (5), 371-378.

Johnson, R.M., Ellis, M.D., Mullin, C.A. et al. (2010) Pesticides and honey bee toxicity - USA. Apidologie, 41 (3), 312-331.

Kessler, S.C., Tiedeken, E.J., Simcock, K.L. et al. (2015) Corrigendum: Bees prefer foods containing neonicotinoid pesticides. Nature, 521 (7550), 74-76.

Klein, A.M., Vaissière, B.E., Cane, J.H. et al. (2007) Importance of pollinators in changing landscapes for world crops. Proc. Biol. Sci. 274 (1608), 303-313.

Kucharski, R., Mitri, C., Grau, Y. et al. (2007) Characterization of a metabotropic glutamate receptor in the honeybee (Apis mellifera): implications for memory formation. Invertebr. Neurosci. 7, 99-108.

Lambin, M., Armengaud, C., Raymond, S. et al. (2001) Imidacloprid-induced facilitation of the proboscis extension reflex habituation in the honeybee. Arch. Insect Biochem. Physiol. 4,129-134.

Letzkus, P., Ribi, W.A., Wood, J.T. et al . (2006) Lateralization of olfaction in the honeybee Apis mellifera. Curr. Biol. 16(14), 1471-1476.

Liao, C.H., He, X.J., Wang, Z.L. et al. (2018) Short-term exposure to lambda-cyhalothrin negatively affects the survival and memory-related characteristics of worker bees Apis mellifera. Arch. Environ. Contam. Toxicol. $75(1), 59-65$.

Liao, C.H., Wu, J., Wang, Z.L. et al. (2017) Effect of fenpropathrin on the viability and homing ability of worker bees Apis mellifera. J. Asia Pac. Entomol. 20 (4), 1063-1066.

Morris, R.G.M., Davis, S., Butcher, S.P. (1990) Hippocampal synaptic plasticity and nmda receptors: a role in information storage? Philos. Trans. R. Soc. B. 329 (1253), 187-204.

Pohorecka, K., Skubida, P., Miszczak, A. et al. (2012) Residues of neonicotinoid insecticides in bee collected plant materials from oilseed rape crops and their effect on bee colonies. J. Apic. Sci. 56(2),115-134.

Schneider, C.W., Tautz, J., Grünewald, B. et al. (2011) RFID tracking of sublethal effects of two neonicotinoid insecticides on the foraging behavior of Apis mellifera. PLoS ONE, 7 (1), 967-975.

Stanley, D.A., Russell, A.L., Morrison, S.J. et al. (2016) Investigating the impacts of field-realistic exposure to a neonicotinoid pesticide on bumblebee foraging, homing ability and colony growth. J. Appl. Ecol. 53 (5), 1440-1449.

Tan, K., Chen, W., Dong, S. et al. (2014) Imidacloprid alters foraging and decreases bee avoidance of predators. PLoS ONE, 9 (7), e102725.

Thany, S.H., Bourdin, C.M., Graton, J. et al. (2015) Similar comparative low and high doses of deltamethrin and acetamiprid differently ilmpair the retrieval of the proboscis extension reflex in the forager honeybee (Apis mellifera) . Insects, 6 (4),805-814.

Thompson, H.M (2003) Behavioural Effects of pesticides in bees-their potential for Use in Risk assessment. Ecotoxicology, 12 (1-4),317.

Thompson, H.M., Thorbahn, D., Oomen, P.A. et al. (2010) Review of honeybee pesticide poisoning incidents in Europe - evaluation of the hazard quotient approach for risk assessment. Julius. Kühn. Archiv. 7(423),103108.

Tomizawa, M., Casida, J.E. (2004) Neonicotinoid insecticide toxicology: mechanisms of selective action. Annu. Rev. Pharmacol. Toxicol. 45,247-268.

Wang, Z.L., Wang, H., Qin, Q.H. et al . (2013) Gene expression analysis following olfactory learning in Apis mellifera. Mol. Biol. Rep. 40 (2), 1631-1639. 
Wu, J.Y., Anelli, C.M., Sheppard, W.S. (2011) Sub-lethal effects of pesticide residues in brood comb on worker honey bee (Apis mellifera) development and longevity. PLoS ONE 6(2), e14720.

Wu-Smart, J., \& Spivak, M. (2016) Sub-lethal effects of dietary neonicotinoid insecticide exposure on honey bee queen fecundity and colony development. Sci. Rep. 6, 32108.

Zachepilo, T.G., Il'Inykh, Y.F., Lopatina, N.G. et al. (2008) Comparative analysis of the locations of the NR1 and
NR2 NMDA receptor subunits in honeybee (Apis mellifera) and fruit fly (Drosophila melanogaster, Canton-S wild-type) cerebral ganglia. Neurosci. Behav. Physiol. 38 (4), 369-372.

Publisher's note Springer Nature remains neutral with regard to jurisdictional claims in published maps and institutional affiliations. 